\title{
Cyclic GMP-dependent protein kinase II is a molecular switch from proliferation to hypertrophic differentiation of chondrocytes
}

\author{
Hirotaka Chikuda, ${ }^{1}$ Fumitaka Kugimiya, ${ }^{1}$ Kazuto Hoshi, ${ }^{1}$ Toshiyuki Ikeda, ${ }^{1}$ Toru Ogasawara, ${ }^{1}$ \\ Takashi Shimoaka, ${ }^{1}$ Hirotaka Kawano, ${ }^{1}$ Satoru Kamekura, ${ }^{1}$ Atsuko Tsuchida, ${ }^{2}$ Norihide Yokoi, ${ }^{2}$ \\ Kozo Nakamura, ${ }^{1}$ Kajuro Komeda, ${ }^{2}$ Ung-il Chung, ${ }^{1}$ and Hiroshi Kawaguchi ${ }^{1,3}$ \\ ${ }^{1}$ Department of Sensory and Motor System Medicine, Faculty of Medicine, University of Tokyo, Bunkyo, Tokyo 113-8655, \\ Japan; ${ }^{2}$ Division of Laboratory Animal Science, Animal Research Center, Tokyo Medical University, \\ Shinjuku, Tokyo 160-8402, Japan
}

\begin{abstract}
The Komeda miniature rat Ishikawa (KMI) is a naturally occurring mutant caused by an autosomal recessive mutation mri, which exhibits longitudinal growth retardation. Here we identified the mri mutation as a deletion in the rat gene encoding cGMP-dependent protein kinase type II (cGKII). KMIs showed an expanded growth plate and impaired bone healing with abnormal accumulation of postmitotic but nonhypertrophic chondrocytes. Ex vivo culture of KMI chondrocytes reproduced the differentiation impairment, which was restored by introducing the adenovirus-mediated cGKII gene. The expression of Sox9, an inhibitory regulator of hypertrophic differentiation, persisted in the nuclei of postmitotic chondrocytes of the KMI growth plate. Transfection experiments in culture systems revealed that cGKII attenuated the Sox9 functions to induce the chondrogenic differentiation and to inhibit the hypertrophic differentiation of chondrocytes. This attenuation of Sox9 was due to the cGKII inhibition of nuclear entry of Sox9. The impaired differentiation of cultured KMI chondrocytes was restored by the silencing of Sox9 through RNA interference. Hence, the present study for the first time shed light on a novel role of cGKII as a molecular switch, coupling the cessation of proliferation and the start of hypertrophic differentiation of chondrocytes through attenuation of Sox9 function.
\end{abstract}

[Keywords: KMI; cGKII; Sox9; chondrocyte; hypertrophy; endochondral ossification]

Received May 20, 2004; revised version accepted August 4, 2004.

Skeletal growth is determined mainly by the process of endochondral ossification in the cartilaginous growth plate, which consists of the resting, proliferative, and hypertrophic zones of chondrocytes, typically in orderly columnar arrays. In this process, chondrocytes that arise from mesenchymal cells undergo proliferation, terminal differentiation into hypertrophic cells, and synthesis of the cartilage matrix, which finally calcifies and is replaced by bone (Kronenberg 2003). The start of hypertrophic differentiation occurs concurrently with the cessation of chondrocyte proliferation. To date, several molecular signalings have been implicated in the switching between proliferation and terminal differentiation in other cell types (Sorrentino et al. 1990; Umek et al. 1991; Tao and Umek 2000); however, the molecular mechanism that couples the cessation of proliferation and the

${ }^{3}$ Corresponding author.

E-MAIL kawaguchi-ort@h.u-tokyo.ac.jp; FAX 81-3-3818-4082.

Article and publication are at http://www.genesdev.org/cgi/doi/10.1101/ gad. 1224204 start of hypertrophic differentiation of chondrocytes remains an enigma.

The Komeda miniature rat Ishikawa (KMI), which was discovered in a closed colony of Wistar rats and was established as a segregating inbred, is a naturally occurring dwarf mutant caused by an autosomal recessive mutation mri (Serizawa 1993). Homozygous mutants (mri/ mri) were born and grew normally until 3-4 wk of age, when they gradually started to develop longitudinal growth retardation without other organ abnormalities. In the present study we identified the mri mutation as a deletion in the rat gene encoding cGMP-dependent protein kinase type II (cGKII) by a positional candidate cloning strategy. cGKII is a membrane-bound kinase which is activated by intracellular cGMP, and is known to be expressed abundantly in the intestinal mucosa, kidney, lung, brain, and cartilage (Ruth 1999; Hofmann et al. 2000). This study further investigated the cellular and molecular mechanisms underlying the impairment of endochondral ossification by the cGKII deficiency. 


\section{Results}

\section{Longitudinal growth retardation in KMI (mri/mri)}

KMIs developed dwarfism with short limbs and trunk compared to the wild-type littermates (Fig. 1A). Growth curves indicated that KMIs started to show the axial growth retardation postnatally at $4 \mathrm{wk}$ of age, although there was no difference between wild-type and heterozygote $(+/$ mri) rats in either sex, confirming an autosomal recessive inheritance (Fig. 1B). The trunk of the KMIs was about $30 \%$ shorter than those of wild-type and $+/ m r i$ littermates at $10 \mathrm{wk}$ of age. Skeletal X-ray analysis at this age revealed no appreciable changes between wild type and KMI in the width of calvarium, which is formed through intramembranous ossification; however, the longitudinal lengths of femora, tibiae, and vertebrae, all of which are formed through endochondral ossification, were $20 \%-30 \%$ shorter in KMI than in wild type (Fig. $1 \mathrm{C}, \mathrm{D})$. In the long bones of KMI, the height of the epiphyseal growth plate was greater than that in wild type, indicating that the growth retardation in KMI resulted from the impairment of endochondral ossification in the growth plate.

\section{Positional cloning of the mri mutation}

We first genotyped simple sequence length polymorphism (SSLP) markers throughout the rat genome on the backcross progeny and detected putative linkage at the D14Rat6 marker on rat chromosone 14. Further genetic mapping localized the mri locus to a 1.2-cM interval on rat chromosome 14 flanked by markers D14Rat5 and D14Rat80. Comparative mapping analysis revealed that the region was orthologous to the regions on mouse chromosome 5 and human chromosome 4, in which several candidate genes including $B m p 3$ and $c G K I I$ (also known as Prkg2) were identified (Fig. 2A). Although the $B m p 3$ gene encoding a bone morphogenetic protein (BMP) first drew our attention, our studies revealed this gene unlikely to be causative of the KMI phenotype. The expression of the $B m p 3$ gene was not different between wild type and KMI, and the sequencing analysis showed only a few silent variants (data not shown). Furthermore, the Bmp3 null mice are reported to exhibit normal body size but increased bone density (Daluiski et al. 2001), which is different from the KMI phenotypes.

We then performed an RT-PCR analysis of the cGKII gene, and found that the cGKII transcript from the brain of the KMI mutant was shorter than that from wild type (Fig. 2B). Sequencing analysis disclosed that exon 3 of the cGKII gene was directly spliced onto exon 6 (Fig. 2C). This 220-bp deletion spanning exons 4 and 5 resulted in a frame shift and a premature stop codon, predicting a truncated product that lacks the entire kinase domain (Fig. 2D). We further carried out inter-exon PCR between exons 3 and 6 of the genomic DNA, and found an $\sim 5-\mathrm{kb}$
A
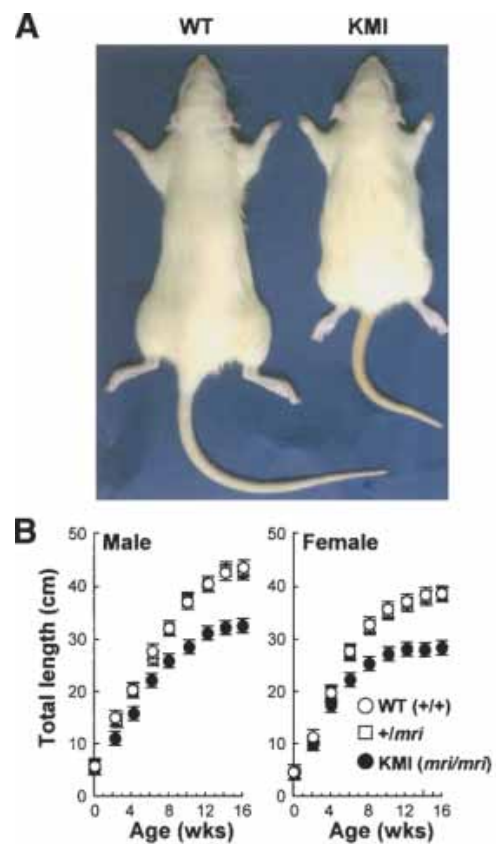

C

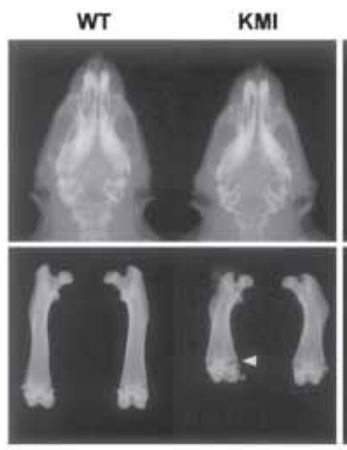

D

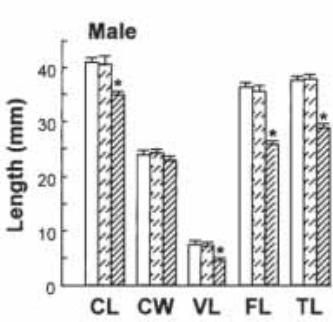

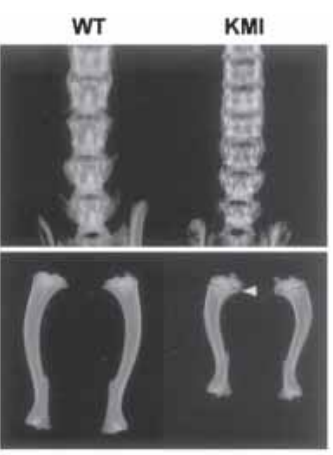

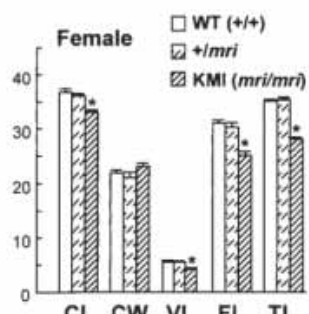

Figure 1. Longitudinal growth retardation in KMI (mri/mri). (A) Gross appearance of wild-type (WT) and KMI littermates at 10 wk of age. $(B)$ Growth curves of wild-type $(\mathrm{WT} ;+/+)$, heterozygote $(+/$ mri $)$, and homozygote (KMI, mri/mri) rats determined by the total axial length (from nose to tail end). The symbols of $+/ m r i$ are behind those of wild-type rats. Data are expressed as means (symbols) \pm S.E.M. (error bars) for 12 rats/group. $(C)$ Plain X-ray images of heads (top left), lumbar vertebrae (top right), femora (bottom left), and tibiae (bottom right) of wild-type (WT) and KMI littermates at $10 \mathrm{wk}$. Arrowheads indicate the expanded growth plates in KMI. $(D)$ Bone lengths of wild type (WT), +/mri, and KMI at 10 wk. (CL) Naso-occipital length of the calvarium; (CW) maximal interparietal distance of the calvarium; (VL) fifth lumbar vertebral length; (FL) femoral length; (TL) tibial length. Data are means (bars) \pm S.E.M. (error bars) for 12 rats/group. $\left({ }^{\star}\right) P<0.05$ vs. wild type. 

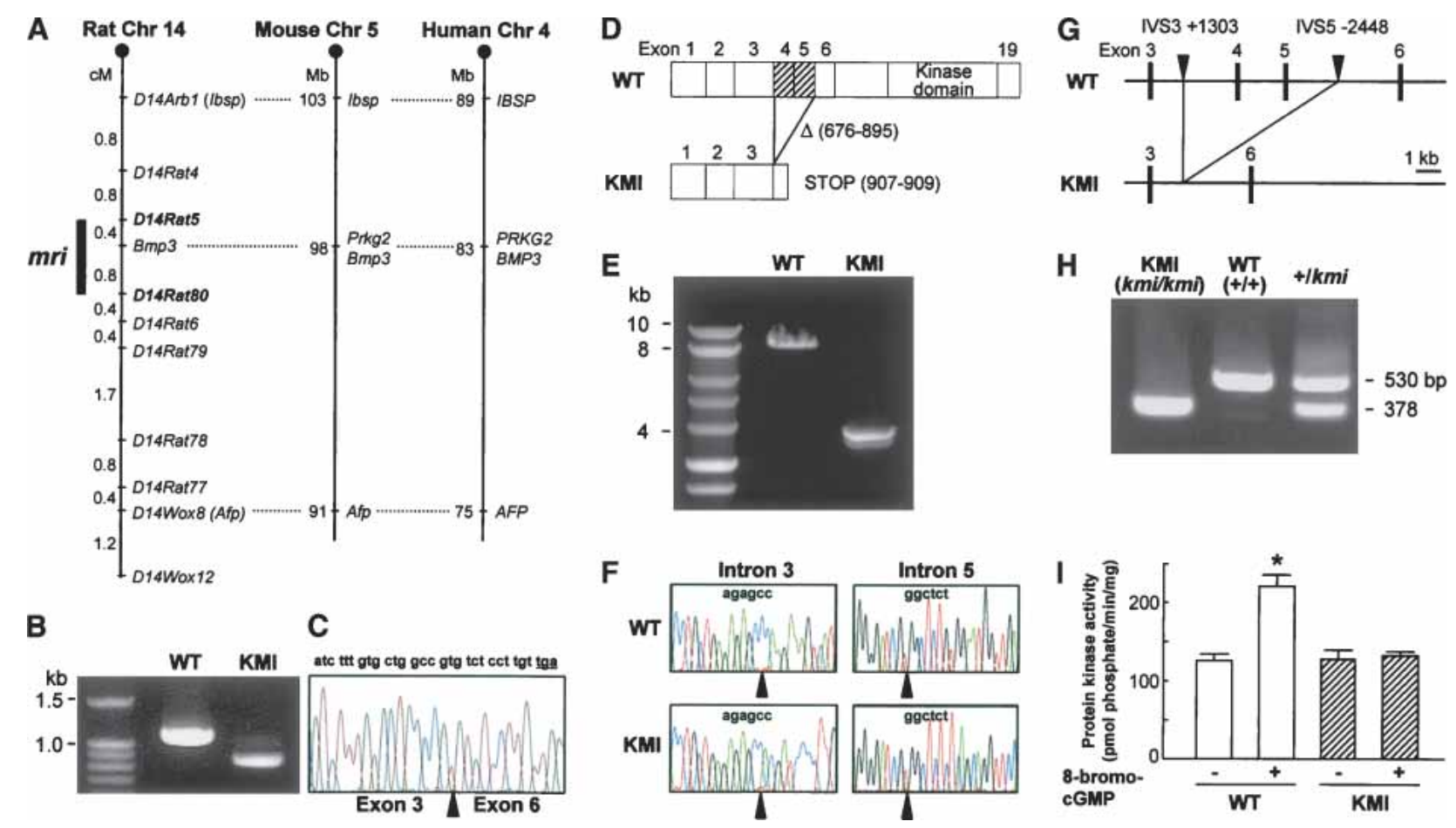

Figure 2. Identification of the mri mutation. (A) Comparative mapping of the mri region in the rat, mouse, and human choromosomes. The mri locus, which was mapped to a 1.2-cM interval between markers D14rat5 and D14rat80, is shown as a bold line. (B) RT-PCR products of the rat cGKII from the brains of wild-type (WT) and KMI littermates. $(C)$ Sequence analysis of transcript of the cGKII gene from the KMI mutant. Exon 3 is directly spliced onto exon 6, with the boundary indicated by the arrowhead. The frame shift causes amino acid substitutions and a premature stop codon. (D) Schematic representation of the prematurely truncated cGKII protein in the KMI mutant. Nucleotide sequence analyses of the cDNA identified a 220-bp deletion (676-895) corresponding to exons 4 and 5. (E) Interexon PCR between exons 3 and 6 using the genomic DNA from wild type (WT) and KMI indicated an $\sim 5-\mathrm{kb}$ deletion in the KMI. $(F)$ Sequence analyses of genomic DNA of wild type (WT) and KMI identified breakpoints in introns 3 and 5 (arrowheads). A common sequence, "AGAGCC", was found at the two breakpoints. (G) Schematic representation of the mri mutation as an $\sim 5$-kb deletion in the $c$ GKII gene. Sequence analyses disclosed the deletion from IVS3+1303 to IVS5-2448 in KMI. (H) Genotyping of KMI (mri/mri), wild-type $(\mathrm{WT} ;+/+$ ), and +/mri rats. A longer amplicon (530 bp) was amplified from wild-type allele, and a shorter amplicon $(378 \mathrm{bp}$ ) from the mutated allele. (I) Lack of cGMP-dependent protein kinase activity of the KMI brain extract determined by the in vitro kinase assay in the presence and absence of 8-bromo-cGMP. Data are means (bars) \pm S.E.M. (error bars) of six samples/group. ( ${ }^{\star}$ ) $P<0.01$, significant effect of 8-bromo-cGMP.

deletion in the $c$ GKII gene of KMI (Fig. 2E). Sequencing analysis identified the breakpoints in introns 3 and 5 , both of which had a common sequence, "AGAGCC" (Fig. 2F), creating a deletion from intervening sequence (IVS)3+1303 to IVS5-2448 (Fig. 2G). To confirm that this deletion in the $c$ GKII gene was responsible for the KMI phenotype, we designed PCR primers to detect this genomic deletion, and found complete cosegregation of the genotypes KMI (mri/mri), wild type $(+/+)$, and $+/$ mri with the phenotypes (Fig. 2H). To test whether the mri mutation in the cGKII gene resulted in loss of its function, tissue extract from brain that is known to express high levels of cGKII was assayed for the kinase activity. The in vitro kinase assay revealed that the wild-type extract showed a significant increase in the kinase activity by the stimulation with the cGMP analog 8-bromo-cGMP; however, the increase was not observed in the KMI extract (Fig. 2I). Taken together, these results strongly suggested that the deletion in the cGKII gene resulted in loss of its function and caused dwarfism in KMI.

\section{Abnormal endochondral ossification in the growth plate and the fracture callus of KMI}

We first investigated the expression pattern of cGKII in the proximal growth plates of the wild-type and KMI tibiae at $10 \mathrm{wk}$ of age. Immunohistochemical analysis of the wild-type growth plate revealed that cGKII was expressed predominantly in the late proliferative and prehypertrophic chondrocytes, preceding the start of hypertrophic differentiation; however, no immunoreactivity for cGKII was observed in the KMI growth plate (Fig. 3A, $\alpha$-cGKII).

To elucidate the cellular mechanisms underlying the dwarfism due to the cGKII dysfunction in KMI, we performed histological analyses of the growth plates. At birth, growth plates showed no discernible difference between wild type and KMI (Fig. 3A, HE, E18.5). Pathological changes gradually became evident postnatally after 4-5 wk of age, and at 10 wk the height of the KMI growth plate was about 2.5-fold greater than that of wild type 
A
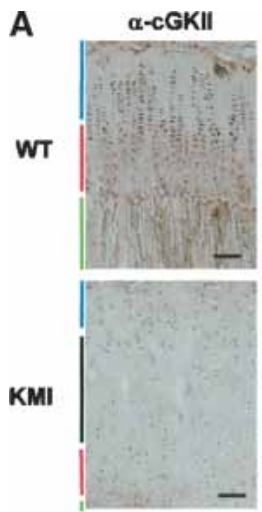

BrdU

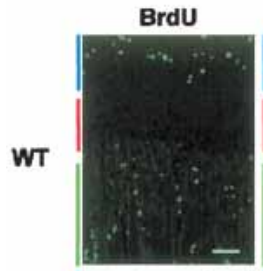

KMI

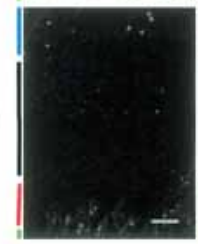

HE (E18.5)
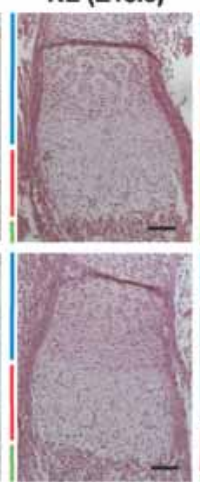

ALP
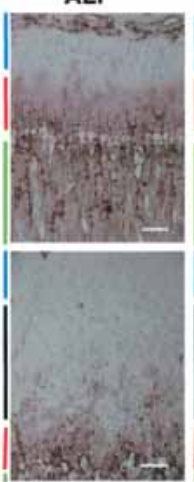

HE

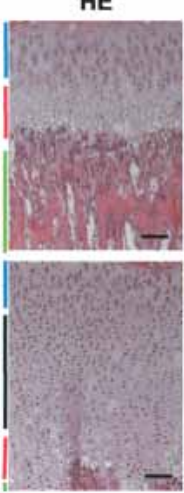

$\alpha-\operatorname{COL10}$
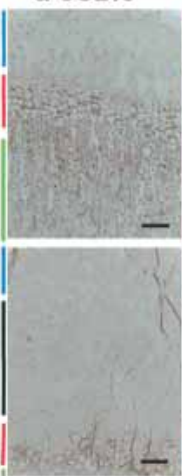

von Kossa
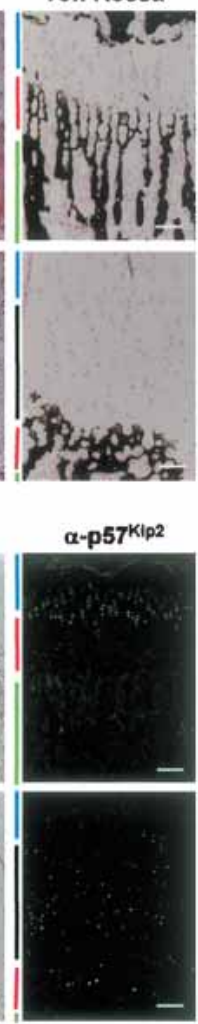

B

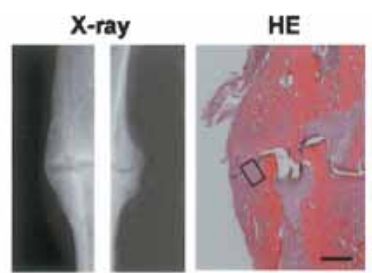

$\alpha-\operatorname{CoL} 10$
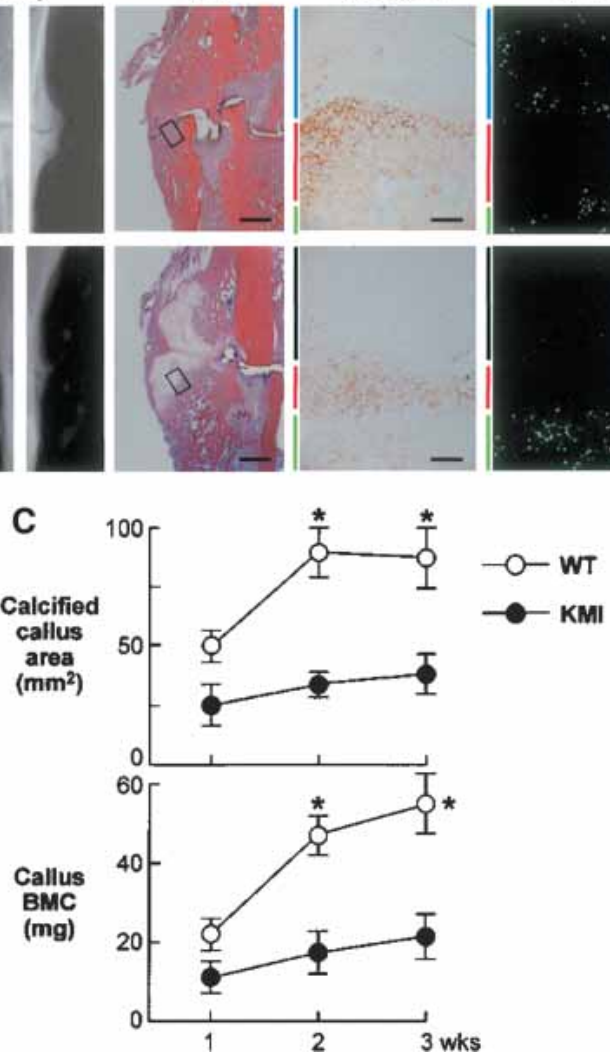

Figure 3. Comparison of endochondral ossification in the growth plate $(A)$ and the bone fracture callus $(B, C)$ between wild type $($ WT $)$ and KMI. Blue, red, and green bars indicate layers of proliferative zone, hypertrophic (including prehypertrophic) zone, and primary spongiosa, respectively. Black bar indictates the abnormal intermediate zone that is seen only in KMI. $(A)$ Histological findings of the proximal growth plates in wild-type (WT) and KMI tibiae at $10 \mathrm{wk}$ of age unless otherwise described. (Upper panel) Immunohistochemical staining with an anti-cGKII antibody $(\alpha$-cGKII), hematoxylin-eosin staining of the humeral growth plates of fetal rats (HE, E18.5), HE staining (HE), and von Kossa staining (von Kossa). (Lower panel) BrdU labeling (BrdU), alkaline phosphatase staining (ALP), immunohistochemical stainings with anti-type X collagen $(\alpha-C O L 10)$, and anti-p5 $7^{\text {Kip2 }}\left(\alpha-\mathrm{p} 57^{\text {Kip2 }}\right)$ antibodies. Bars, $50 \mu m$. (B) Radiological and histological findings of the fracture callus $2 \mathrm{wk}$ after the surgery. After exposing the right tibiae of 10-week-old rats, a transverse osteotomy was performed at the midshaft with a bone saw and was stabilized with an intramedullary nail. Plain X-ray images (X-ray), HE staining (HE; inset boxes indicate the regions of the right two figures), immunohistochemical staining with an anti-type X collagen antibody ( $\alpha$-COL10), and BrdU labeling (BrdU). Bars: HE, $500 \mu \mathrm{m}$; right two figures, $50 \mu \mathrm{m}$. $(C)$ Time course of the calcified area and the bone mineral content (BMC) of the callus at the fracture site measured by a single energy X-ray absorptiometry. Data are mean (symbols) \pm S.E.M. (error bars) of eight rats/genotype. $\left(^{*}\right) P<0.01$ vs. wild type.

(665 $\pm 47 \mu \mathrm{m}$ vs. $255 \pm 34 \mu \mathrm{m}$, mean \pm S.E.M., $n=8$, respectively), although the columnar structure was relatively preserved (Fig. 3A, HE). This increase was due to an intermediate layer of accumulated abnormal chondrocytes in the KMI growth plate (Fig. 3A, HE, black bar). Although the cell size of chondrocytes in the KMI hypertrophic zone seemed somewhat smaller than that in wild type, matrix mineralization determined by von Kossa staining appeared normal in KMI (Fig. 3A, von Kossa).

To further characterize the abnormal chondrocytes in the intermediate layer of the KMI growth plate, we examined cellular proliferation by the the uptake of BrdU. In wild type, chondrocytes in the proliferating zone and bone marrow cells in the primary spongiosa were actively proliferating as detected by the BrdU uptake (Fig. 3A, BrdU). In KMI, the number of BrdU-positive cells was slightly decreased in the proliferating zone, and more importantly, no uptake was observed in the intermediate layer, suggesting that these abnormal chondrocytes were postmitotic. We next examined the distributions of alkaline phosphatase (ALP) and type X collagen (COL10) as markers of prehypertrophic and hypertrophic chondrocytes, respectively. Histochemical analyses of the wild-type growth plate revealed that these markers were expressed immediately after the BrdU uptake had disappeared, confirming the coupling of the cessation of proliferation and the start of hypertrophic differentiation (Fig. 3A, ALP and $\alpha$-COL10). In the KMI growth plate, however, the intermediate layer was stained by neither of the markers, indicating that these abnormal chondrocytes had not started hypertrophic differentiation. In addition, expression of $\mathrm{p} 57^{\mathrm{Kip} 2}$, a key regulator of cell-cycle arrest and differentiation of chondrocytes (Yan et al. 
1997; Stewart et al. 2004) was limited to the boundary of proliferative and hypertrophic zones in the wild-type growth plate (Fig. 3A, $\alpha$-p5 $7^{\text {Kip2 }}$ ), whereas in KMI the p5 $7^{\mathrm{Kip} 2}$-expressing cells were broadly and sporadically scattered in the intermediate layer, suggesting a loss of synchronized withdrawal from the cell cycle of the chondrocytes. Hence, the intermediate layer chondrocytes were abnormal cells that had ceased proliferation but had not started hypertrophic differentiation.

To examine whether cGKII has an important role generally for endochondral ossification, we compared the healing process of bone fracture produced by a transverse osteotomy and stabilized with an intramedullary nail at the midshaft of tibiae of wild type and KMI (Shimoaka et al. 2004). X-ray analysis 2 wk after the fracture showed substantial calcified callus formation in wild type, which was rarely seen in KMI (Fig. 3B, X-ray). Time course analyses of the calcified area and the bone mineral content (BMC) of the callus measured by a bone densitometer revealed the impairment of endochondral ossification in KMI at 2 wk and thereafter (Fig. 3C). Histological analysis at $2 \mathrm{wk}$ confirmed that endochondral ossification was present in the wild-type fracture callus; in KMI, however, massive uncalcified cartilagenous callus remained, although intramembranous ossification from the periosteum was normally seen (Fig. 3B, HE). When distributions of hypertrophic and proliferating chondrocytes were examined by the COL10 immunostaining and the BrdU uptake, respectively, the two kinds of cells were located adjacent to each other in the wildtype callus, indicating the tight coupling between proliferation and hypertrophic differentiation in this model as well (Fig. 3B, $\alpha$-COL10 and BrdU). In the KMI callus, there was an intermediate layer with an accumulation of abnormal cells that were stained by neither marker (Fig. 3B, black bars), as observed in the growth plate.

Taking these histological findings together, the cessation of proliferation and the start of hypertrophic differentiation, which were tightly coupled under normal conditions, were dissociated in both the growth plate and the fracture callus of KMI. The cGKII dysfunction was therefore shown to impair the synchronized switching from proliferation to hypertrophic differentiation of chondrocytes in the endochondral ossification.

\section{Functions of cultured chondrocytes from KMI growth plate}

To investigate the mechanism underlying the abnormality of chondrocytes due to the cGKII deficiency, ex vivo cultures of primary chondrocytes isolated from the proximal growth plates of the wild-type and KMI tibiae were performed. We first compared the time course of cell proliferation determined by the growth curve for $8 \mathrm{~d}$, and found no significant difference between wild-type and KMI chondrocytes (Fig. 4A). However, after $5 \mathrm{~d}$ of culture when the chondrocytes became confluent, the cell shape by the phase contrast image was different between wild type and KMI: The former was hexagonal whereas the latter showed a spindle-shape appearance
(Fig. 4B). ALP staining revealed that the KMI chondrocytes were less differentiated than wild type. In addition, a real-time RT-PCR analysis revealed that the expression of COL10, a marker for hypertrophic differentiation, was down-regulated in cultured KMI chondrocytes compared to wild-type chondrocytes. To confirm the contribution of cGKII to these abnormalities, cGKII was introduced into cultured KMI chondrocytes using an adenovirus vector carrying the $c G K I I$ gene $(\mathrm{Ax}-c G K I I)$. As a result, the suppression of all of these differentiation markers in the KMI culture was restored to those similar to the wild-type culture, although introduction of the same adenovirus vector without the $c$ GKII gene (Ax-vector) did not affect them (Fig. 4B).

We next examined the involvement of cGKII in the putative signalings which regulate hypertrophic differentiation of chondrocytes (Fig. 4C,D). PTH/PTHrP via the cAMP-dependent protein kinase (PKA) is known to be a major signal in the inhibition of chondrocyte hypertrophy (Chung and Kronenberg 2000). PTHrP and PTH/ PTHrP receptor levels were similar between the wildtype and KMI cultures, and PTH/PTHrP signaling determined by the dose-response effect of PTH on cAMP accumulation was not enhanced in the KMI chondrocyte culture compared to the wild-type culture, indicating that the impaired differentiation of the KMI chondrocytes is not due to a defect of the inhibition by cGKII on the PTH/PTHrP signaling (Fig. 4C). C-type natriuretic peptide (CNP) is also known to be a positive regulator of endochondral ossification and a putative ligand for cGKII (Chusho et al. 2001; Miyazawa et al. 2002). Addition of CNP failed to rescue either the impaired ALP activity or the COL10 expression in the KMI chondrocyte culture (Fig. 4D), indicating that cGKII plays a role in CNP-mediated chondrocyte differentiation. On the other hand, BMP-2 potently increased these differentiation markers, suggesting that the BMP signaling molecules Smads and Runx2 may be independent of the cGKII signaling (Fig. 4D). These results demonstrate that cGKII is not involved in the two major signalings of chondrocyte hypertrophy: PTH/PTHrP and BMP.

\section{cGKII as an attenuator of Sox9 function}

We further examined the involvement of cGKII in the function of Sox9, a transcription factor that is known to be essential for chondrogenic differentiation of mesenchymal cells (de Crombrugghe et al. 2001). Sox9 also functions as a potent inhibitor of the hypertrophic differentiation of chondrocytes (Akiyama et al. 2002), and the expression disappears at the hypertrophic zone in the growth plate (Huang et al. 2000). In line with previous studies, our immunohistochemical study confirmed the lack of Sox9 localization in the hypertrophic zone of the wild-type growth plate; however, nuclear localization of Sox9 was clearly visible in the abnormal intermediate layer of the KMI growth plate (Fig. 5A).

To assess the possible interaction between cGKII and Sox9, we performed transfection experiments with plasmids encoding cGKII and/or Sox9 in cell culture sys- 
A
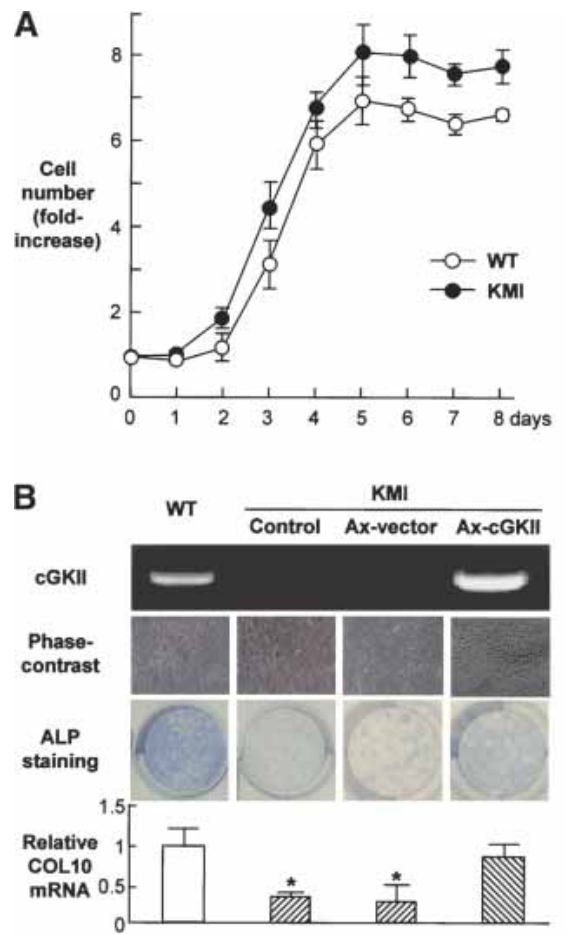

C

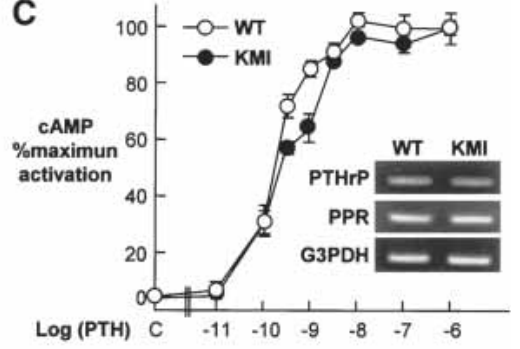

D

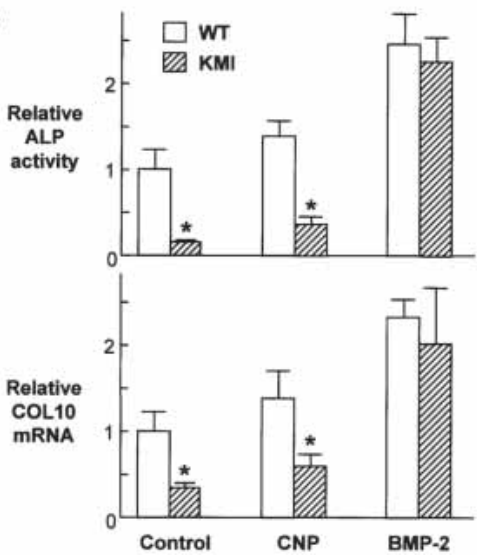

Figure 4. Functions of cultured chondrocytes from wild type and KMI. (A) Growth curves of wild-type (WT) and KMI chondrocytes isolated from the growth plate. Data are mean (symbols) \pm S.E.M. (error bars) of six dishes/genotype. Lack of significant difference between the genotypes was confirmed in five independent experiments. $(B)$ Differentiation of wild-type (WT) and KMI chondrocytes determined by the phase contrast image, ALP staining, and COL10 mRNA level determined by real-time quantitative RT-PCR cultured for 5, 21, and 28 $\mathrm{d}$, respectively. As a rescue experiment, an adenovirus vector carrying the $c G K I I$ gene (Ax-cGKII) or that without the cGKII gene (Ax-vector) was introduced into KMI chondrocytes. (Top panel) The cGKII mRNA level is shown by RT-PCR. COL10 mRNA levels are mean (bars) \pm S.E.M. (error bars) of the relative amount of mRNA compared to that of wild type of six wells/group. $\left({ }^{\star}\right)$ $P<0.05$ vs. wild type. $(C)$ PTH/PTHrP signaling determined by the dose-response effects of PTH $\left(10^{-11}\right.$ to $\left.10^{-6} \mathrm{M}\right)$ on cAMP accumulation in wild-type (WT) and KMI chondrocytes. Data are mean (symbols) \pm S.E.M. (error bars) of the percentages of maximal cAMP activation for six wells/genotype. Lack of significant difference between the genotypes was confirmed in three independent experiments. The PTHrP and PTH/PTHrP receptor (PPR) mRNA levels are shown by RT-PCR as an inset. (D) Effects of CNP (100 nM) and BMP-2 (100 ng/mL) on the ALP activity and COL10 mRNA level determined by real-time quantitative RT-PCR in the wild-type (WT) and KMI chondrocyte cultures for 21 and 28 d, respectively. Data are mean (bars) \pm S.E.M. (error bars) of six wells/group. $\left({ }^{\star}\right) P<0.01$ vs. wild type.

tems. Initially, to know the effects of cGKII and Sox9 on the hypertrophic differentiation of chondrocytes, we examined the COL10 expression in cultured mouse chondrogenic ATDC5 cells (Fig. 5B; Shukunami et al. 1996). In the monolayer culture, the baseline of the COL10 level was low and little altered by the Sox 9 transfection; however, in the three-dimensional culture, ATDC5 cells differentiated into hypertrophic chondrocytes with COL10 expression in the presence of insulin, as reported previously (Seki et al. 2003). The Sox9 transfection was confirmed to reduce the COL10 mRNA level, and the cotransfection with cGKII restored it to the control level. In addition, transfection with Sox 9 was also confirmed to show an $\sim 10$-fold increase in the type II collagen (COL2) mRNA level in human nonchondrogenic hepatoma HuH-7 cells, and cotransfection with cGKII significantly suppressed the Sox9-induced COL2 expression (Fig. 5C). These results suggest a novel function of cGKII as an attenuator of the Sox9 actions: inhibition of hypertrophic differentiation and stimulation of chondrogenic differentiation. We further examined the effects of mutated cGKII: one derived from KMI (cGKII-KMI) and the other lacking the entire kinase domain (cGKII- $\Delta$ kinase) in the respective cultures (Fig. 5B,C). Neither of the mutant cGKIIs restored the Sox9-inhibited COL10 level nor suppressed the Sox9-induced COL2, implicating that the kinase activity of cGKII was indispensable for the attenuation of the Sox9 function. Hence, we next exam- ined the involvement of phosphorylation of Sox9 in the action of cGKII. The consensus amino acid sequence for phosphorylation by cGKII is RRXS/TX where either S or $\mathrm{T}$ is the phosphorylation site (Hofmann 1995), and a single consensus sequence was detected at Ser 181 (S181) in the human Sox9. Immunoblot analysis with a phosphorylation-specific antibody revealed that the cGKII cotransfection stimulated the phosphorylation of transfected Sox9 at S181 in HuH-7 cells (Fig. 5D, top panel). To learn the functional relevance of the Sox 9 phosphorylation by cGKII, we generated a phosphorylation-deficient Sox9 vector (Sox9 $9^{\text {S181A }}$ ) by introducing serine-toalanine substitutions at S181. The Sox $9^{\text {S181A }}$ transfection induced the COL2 expression to a level similar to that of the wild-type Sox9 in HuH-7 cells (Fig. 5D, bottom panel). Interestingly, the cGKII cotransfection decreased the COL2 induction by the Sox $9^{\text {S181A }}$ similarly to that by the wild-type Sox9, indicating that the phosphorylation of Sox9 itself is dispensable for the attenuation of the Sox9 function by cGKII.

To clarify the mechanism underlying the attenuation of the Sox 9 signaling by cGKII, we examined the subcellular localization of Sox9. Fluorescent images of HeLa cells transfected with the plasmid encoding GFP-Sox9 revealed that Sox9 is predominantly localized in the nucleus, in agreement with previous reports (Fig. 6A; Huang et al. 2001). When cGKII was cotransfected, Sox9 became localized not only in the nucleus, but also in the 
Chikuda et al.

A
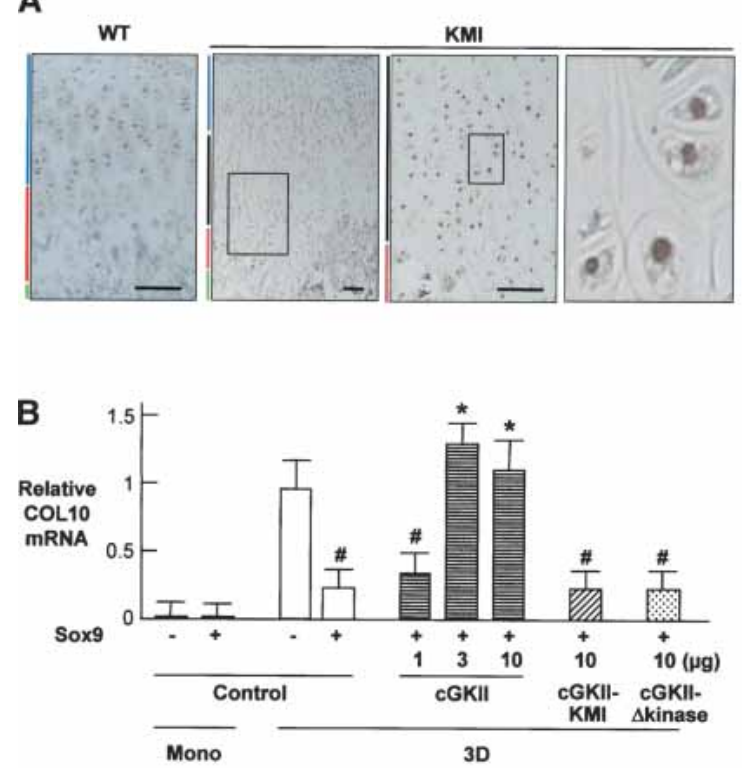

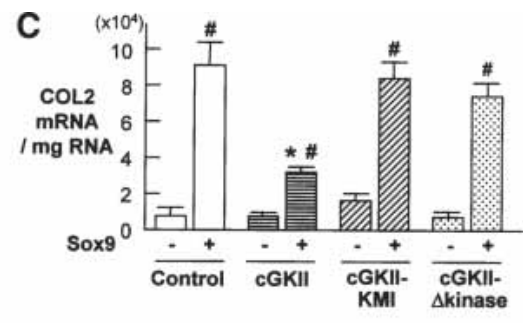

D

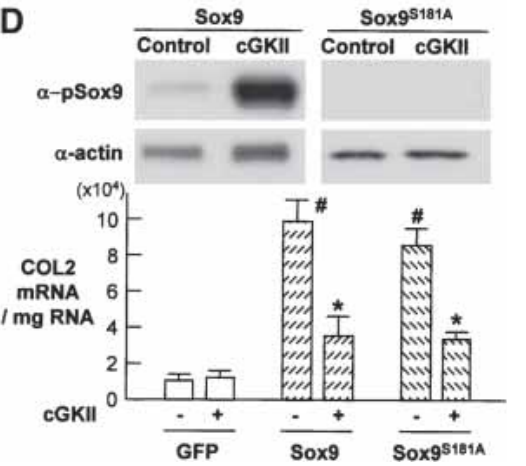

Figure 5. Regulation of Sox9 function and phosphorylation by cGKII. (A) Immunohistochemical stainings with an anti-Sox9 antibody in the growth plates of the proximal tibiae of wild type (WT) and KMI at $10 \mathrm{wk}$ of age. Inset boxes in the middle two panels indicate the regions of the respective right panels. Blue, black, red, and green bars indicate layers of proliferative zone, abnormal intermediate zone, hypertrophic zone, and primary spongiosa, respectively. Bar, $50 \mu \mathrm{m}$. (B) COL10 mRNA levels by the transfection with the plasmid encoding Sox 9 determined by real-time quantitative RT-PCR in cultured ATDC5 cells cotransfected with the empty vector (control), the expression vectors of cGKII $(1,3$ and $10 \mu \mathrm{g})$, cGKII-KMI $(10 \mu \mathrm{g})$, and cGKII- $\Delta$ kinase $(10 \mu \mathrm{g})$ in the monolayer culture (Mono) and three-dimensional alginate beads culture (3D) in the chondrogenic medium with insulin. Data are mean (bars) \pm S.E.M. (error bars) of six wells/group. (\#) $P<0.01$, significant inhibition by Sox $9 .\left(^{\star}\right) P<0.01$, significant stimulation by cGKII. (C) Induction of COL2 mRNA by the Sox9 transfection determined by real-time quantitative RT-PCR in cultured HuH-7 cells cotransfected with the empty vector (control), the expression vectors of wild-type cGKII (cGKII), the mutated cGKII lacking exons 4 and 5 (cGKII-KMI), and that lacking the kinase domain (cGKII- $\Delta$ kinase). Data are mean (bars) \pm SEM (error bars) of six wells/group. (\#) $P<0.01$, significant stimulation by Sox9. $\left(^{\star}\right) P<0.01$, significant inhibition by cGKII. $(D$, top) Immunoblotting with an anti-phosho-Sox9 antibody $(\alpha-$

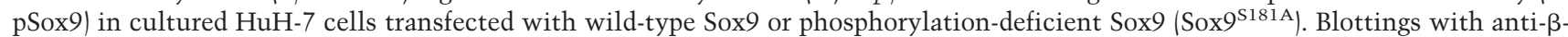
actin ( $\alpha$-actin) were used as loading control. (Bottom) Induction of COL2 mRNA by the transfection with Sox 9 or Sox $9^{\text {S181 A }}$ determined by real-time quantitative RT-PCR in cultured HuH-7 cells in combination with the cGKII expression vector $(+)$ or the empty vector $(-)$. Data are mean (bars) \pm S.E.M. (error bars) of six wells/group. $(\#) P<0.01$, significant stimulation by Sox9. $\left({ }^{\star}\right) P<0.01$, significant inhibition by cGKII.

cytoplasm. Addition of leptomycin B, an inhibitor of CRM-1-dependent nuclear export (Gasca et al. 2002), failed to restore the altered localization of Sox9, suggesting that cGKII attenuated the nuclear entry of Sox9 rather than enhanced its export from the nucleus. As cGKII also altered the subcellular localization of phosphorylation-deficient Sox $9\left(\operatorname{Sox}^{\mathrm{S} 181 \mathrm{~A}}\right)$ in a similar manner, phosphorylation at S181 was shown to be dispensable for this regulatory mechanism. Interestingly, the subcellular localization of Sox 5 and Sox6, critical partners of Sox9, was not affected by cGKII (Fig. 6A). The altered subcellular localization of Sox9 was confirmed by an immunoblot analysis: the cGKII cotransfection increased the Sox9 protein level in the cytoplasmic fraction although it decreased that in the nuclear fraction (Fig. 6B). To determine whether or not the attenuated Sox9 signaling by cGKII was attributable to the decreased nuclear entry of Sox9, we fused Sox9 with SV40derived nuclear localization signal (Sox9-3xNLS), thereby forcing Sox9 to localize in the nucleus. The cGKII cotransfection was unable to keep the Sox9 in the cytoplasm in HeLa cells (Fig. 6C, left panel). In this condition, the inhibitory effect of cGKII on the Sox9-induced COL2 expression was greatly alleviated, indicating that cGKII attenuated the Sox9 function mainly, if not exclusively, by interfering with its nuclear entry (Fig. $6 \mathrm{C}$, right panel). To further examine the change of Sox 9 subcellular localization in the KMI chondrocytes, we adenovirally transduced cultured primary chondrocytes from wild-type and KMI growth plates with GFP-Sox9. Treatment with the cGMP analog 8-bromo-cGMP inhibited nuclear entry of Sox9 in wild-type cells, whereas it did not in KMI cells. CNP, a putative upstream molecule of cGKII, showed a similar effect on the Sox9 subcellular localization in wild-type cells, but not in KMI cells (Fig. 6D). Finally, we examined the effects of the silencing of Sox9 through RNA interference (RNAi) on the cultured growth plate chondrocytes from KMI (Fig. 6E). The impaired differentiation of KMI chondrocytes determined by the ALP staining and the COL10 mRNA level was reversed by the retrovirus-mediated introduction of Sox 9 RNAi. Taken together, these results demonstrate that 
A
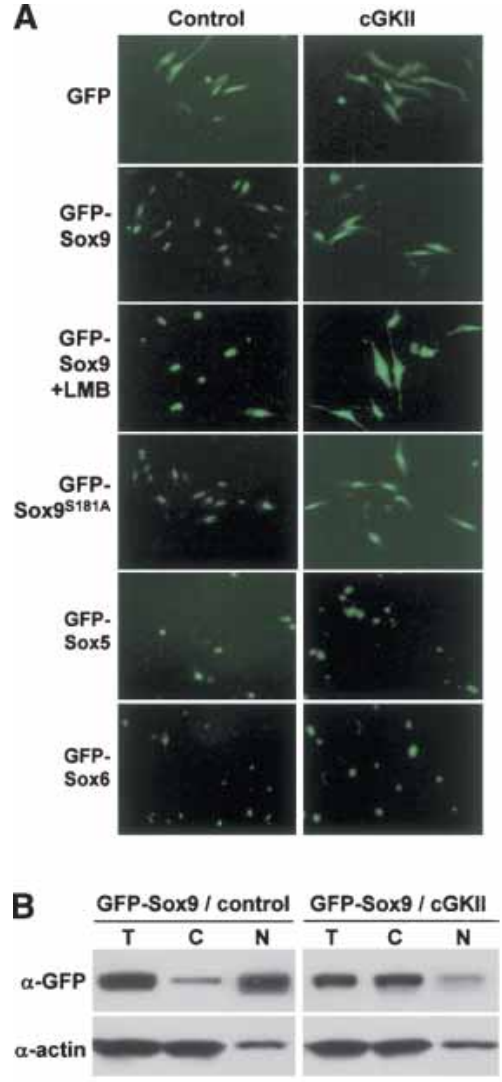

C
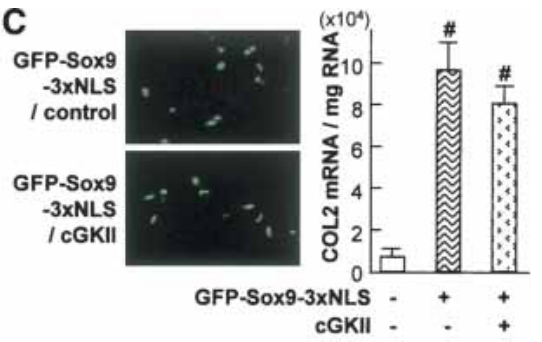

D Control

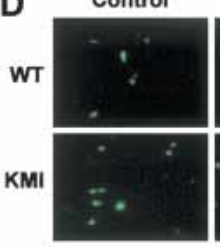

cGMP

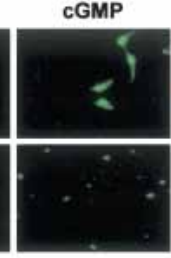

CNP

E

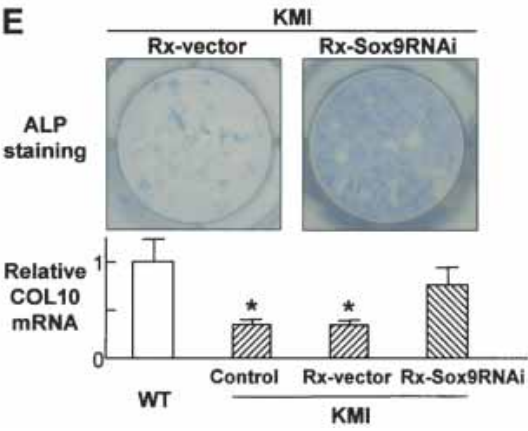

Figure 6. Regulation of Sox 9 function and subcellular localization by cGKII. (A) Fluorescent images of HeLa cells cotransfected with cGKII and Sox9, Sox5, or Sox6. Cells were transfected with plasmids encoding GFP, GFP-tagged Sox9 (GFP-Sox9) in the presence and absence of a nuclear export inhibitor leptomycin (LMB; $2 \mathrm{ng} / \mathrm{mL}$ ), and GFP-Sox9 $9^{\text {S181A }}$, GFP-Sox5, and GFP-Sox6 in combination with the cGKII expression vector or the empty vector (control). (B) Subcellular localization of Sox9 in HeLa cells by immunoblotting. GFP-Sox 9 was cotransfected with the cGKII expression vector or the empty vector (control). The Sox 9 protein levels in the total cell lysate $(T)$, cytoplasmic fraction $(C)$, and nuclear fraction $(\mathrm{N})$ were determined by immunoblotting with an anti-GFP antibody $(\alpha-$ GFP). Blottings with anti- $\beta$-actin ( $\alpha$-actin) were used as loading controls. $(C$, left $)$ Fluorescent images of HeLa cells transfected with the nuclear-localizing Sox9 vector. Three tandem repeats of SV40-derived nuclear localizing signal (NLS) were introduced into the GFP-Sox9 vector (GFP-Sox9-3xNLS). Cells were transfected with the GFP-Sox9-3xNLS in combination with the cGKII expressing vector or the empty vector (control). (Right) Induction of COL2 mRNA by the GFP-Sox9$3 \times$ NLS transfection determined by real-time quantitative RT-PCR in cultured HuH-7 cells cotransfected with the cGKII expression vector $(+)$ or the empty vector $(-)$. Data are mean (bars) \pm S.E.M. (error bars) of six wells/group. (\#) $P<0.01$, significant stimulation by GFP-Sox9-3xNLS. (D) Fluorescent images of wild-type (WT) and KMI growth plate chondrocytes transduced with GFP-Sox9 adenovirus vector. Primary chondrocytes were cultured in the presence and absence of 8-Bromo-cGMP (100 $\mu M)$ or CNP (100 nM). (E) Effects of the silencing of Sox9 through RNAi on the ALP staining and the COL10 mRNA level determined by real-time quantitative RT-PCR in the KMI chondrocyte culture for 21 and 28 d, respectively. The Sox9 RNAi was introduced into KMI chondrocytes using an retrovirus vector carrying the Sox9 RNAi gene (Rx-Sox9RNAi). Retrovirus vector without the the Sox9 RNAi gene (Rx-vector) was used as control. Data are mean (bars) \pm S.E.M. (error bars) of six wells/group. $\left(^{\star}\right) P<0.01$ vs. wild type.

the cGKII dysfunction in KMI impaired the hypertrophic differentiation of chondrocytes through enhancement of the Sox 9 signaling.

\section{Discussion}

Although postproliferative chondrocytes immediately undergo hypertrophic differentiation during endochondral ossification, little has been known about the molecular mechanism that couples the cessation of proliferation and the start of hypertrophy. The present study for the first time identified a novel role of cGKII as a molecular switch for the coupling. The study began with the identification of a mutation in the cGKII gene causing the longitudinal growth retardation of a rat dwarf model, KMI. Analyses of the growth plate and the bone fracture callus of KMI revealed that the cessation of proliferation and the start of hypertrophic differentiation of chondrocytes were dissociated. Cultures of KMI chondrocytes confirmed that the cGKII dysfunction impairs the synchronized switching from proliferation to hypertrophic differentiation. This KMI chondrocyte abnormal- ity may be due to the sustained activity of Sox9, as cGKII was shown to function as an attenuator of Sox9 mainly by inhibiting its nuclear entry.

\section{Physiological function of cGKII}

In mammalian cells, at least three receptors for cGMP are present, that is, cGMP-regulated PDEs, cyclic nucleotide-gated cation channels, and cGKs (Ruth 1999). Mammalian cGKs exist as two isoforms, cGKI and cGKII (Hofmann et al. 2000). Whereas the cGKI is expressed at high levels in all types of smooth muscle, platelets, and cerebellar cells, cGKII is expressed in the intestinal mucosa, juxtaglomerular cells of the kidney, and chondrocytes (Pfeifer et al. 1996). The widespread expression of cGKs is mirrored by the diversity of their functions, which establish these enzymes as major mediators of the cGMP signaling cascade. Studies on the ablation of the genes disclosed the pivotal tasks of these enzymes under in vivo conditions (Pfeifer et al. 1996, 1998). cGKII-deficient $\left(c G K I I^{-1-}\right)$ mice were reported to develop dwarfism postnatally, which was caused by a severe defect in en- 
dochondral ossification at the growth plates (Pfeifer et al. 1996). Although the phenotypes were quite similar to those of KMI, the abnormal population of chondrocytes in the $c G K I I^{-/-}$growth plate was though to constitute a hypertrophic zone with patches of nonhypertrophic cells intermingled with hypertrophic chondrocytes. Our more detailed histological examination of the KMI growth plate clearly showed that these cells were postmitotic but nonhypertrophic chondrocytes. Further examinations of the $c G K I I^{-/-}$growth plate would probably reveal similar findings confirming the unique role of cGKII in the coupling of chondrocyte proliferation and differentiation.

\section{cGKII and CNP signaling}

CNP is a positive regulator of endochondral ossification through the intracellular accumulation of cGMP, which activates different signaling mediators such as cyclic nucleotide phosphodiesterases, cGMP-regulated ion channels, and cGKs (Fowkes and McArdle 2000). Among them, cGKII is reported to play a critical role in the CNP action on endochondral ossification, because targeted expression of CNP in the growth plate chondrocytes failed to rescue the skeletal defect of $c \mathrm{GKII}^{-/-}$mice (Miyazawa et al. 2002). This notion was supported by the present findings that CNP neither reverses the impaired differentiation (Fig. 4D) nor inhibits the Sox9 nuclear entry (Fig. 6D) in cultured KMI chondrocytes. However, there is a marked difference between $\mathrm{CNP}^{-/-}$and $c \mathrm{GKII}^{-/-}$ mice in the histology of the growth plate (Pfeifer et al. 1996; Chusho et al. 2001): the growth plate of the former is reduced in height with the chondrocytes arranged in a regular columnar array, whereas that of the latter is increased in height. This may indicate the involvement of other signaling pathway(s) in the CNP-mediated endochondral ossification. In fact, a recent report showed that targeted overexpression of CNP in chondrocytes prevented the shortening of achondroplastic bones through inhibition of the mitogen-activated protein (MAP) kinase pathway of activated fibroblast growth factor receptor 3 signaling in the growth plate (Yasoda et al. 2004). In addition, the possibility of the involvement of cGKI cannot be ruled out, although no skeletal abnormality has been reported in $c G K I^{-/-}$mice (Pfeifer et al. 1998). It would be helpful to investigate whether mice doubly deficient for $c G K I$ and $c G K I I$ mimic the phenotype of $C N P^{-/-}$mice.

\section{cGKII and PTH/PTHrP signaling}

Targeted expression of a constitutively active PTH/ PTHrP receptor delays endochondral ossification through ligand-independent constitutive cAMP accumulation and the subsequent cAMP-dependent protein kinase (cAK) activation (Schipani et al. 1997). The growth plate histology of the transgenic mice expressing a constitutively active $\mathrm{PTH} / \mathrm{PTHrP}$ receptor is characterized by the irregular and broadened zone lacking the COL10 expression, which is similar to that of $\mathrm{KMI}$ and $c G K I I^{-/-}$ mice. In the present study, however, neither the expression levels of PTHrP and $\mathrm{PTH} / \mathrm{PTHrP}$ receptor nor the cAMP accumulation by PTH stimulation was enhanced in the cultured KMI chondrocytes. It is therefore speculated that the cGKII and $\mathrm{PTH} / \mathrm{PTHrP} / \mathrm{cAK}$ signaling pathways independently coordinate to control the rate of chondrocytic differentiation as an accelerator and a decelerator, respectively.

\section{Regulation of Sox9 actions by cGKII}

In addition to its essential roles in early mesenchymal condensation and development of premature chondrocytes, Sox9 is reported to prevent hypertrophic differentiation of chondrocytes (de Crombrugghe et al. 2001; Akiyama et al. 2002). Although the present findings demonstrated that cGKII maintains the hypertrophy by attenuating the Sox9 activity, the molecular mechanism remains to be clarified in more detail. The fact that cGKII lacking the kinase activity did not suppress the Sox 9 function suggests that phosphorylation by cGKII is required for the regulation of Sox 9 activity. Although cGKII enhanced the phosphorylation of Sox9 at S181, which has been known to be a phosphorylation target for PKA signaling (Huang et al. 2000), the attenuation of Sox9 by cGKII was not dependent on the phosphorylation at this site (Fig. 5D). Along with S181, Ser 64 (S64) is also known to be a phosphorylation target for PKA (Huang et al. 2000); however, this site does not contain the consensus sequence for phosphorylation by cGKII (RRXS/TX). In addition, cGKII suppressed the COL2 induction in cultured HuH-7 cells transfected with a phosphorylation-deficient Sox9 vector at this site (Sox $9^{\text {S64A) }}$ as with the wild-type Sox9 or Sox9 $9^{\text {s181A }}$ (data not shown), indicating that the direct phosphorylation of Sox9 is dispensable for its attenuation by cGKII. Several lines of evidence indicated that transcriptional factors of the Sox family are regulated by subcellular distribution (Sudbeck and Scherer 1997; Harley et al. 2003). The present findings also indicate that cGKII attenuates the Sox9 function at least in part by inhibiting its nuclear entry. Because this cGKII effect was seen in cells transfected with the phosphorylation-deficient Sox9, the phosphorylation and the nuclear entry of Sox 9 were independent, although both were affected by cGKII. Hence, there seem to be other phosphorylation target molecules that mediate cGKII signaling. Sox genes including Sox9 require partner molecules that enhance or suppress transcriptional activities. For example, Sox 5 and Sox 6 cooperatively work with Sox 9 and activate several cartilage matrix genes (Lefebvre and deCrombugghe 1998); however, our computer search found no amino acid sequence in Sox 5 or Sox6 for a cGKII phosphorylation site like S181 in Sox9. Furthermore, our results revealed that their subcellular localizations were not altered by cGKII (Fig. 6A), suggesting that it is unlikely that Sox 5 and Sox 6 are the direct target of cGKII. It was recently revealed that the dimerization of Sox9 is critical for its several target genes. Sox9 contains a dimerization domain and binds 
cooperatively as a dimer in the presence of the DNA enhancer element in genes involved in chondrocyte differentiation, such as COL9, COL11, and CD-Rap (Sock et al. 2003). Because in vitro-transcripted Sox 9 was unable to form a DNA-dependent dimer (Lefebvre et al. 1998), there must be cofactor(s) that mediate the dimerization of Sox9. Although phosphorylation of these partner molecules remains to be resolved, one of these molecules might be a direct or indirect phosphorylational target of cGKII.

cGKII, a molecular switch from proliferation to hypertrophic differentiation of chondrocytes, could be a novel therapeutic target for disorders of skeletal growth and regeneration. Because cGKII is an intracellular kinase, we are planning to apply the gene transfer system that we are now intensively working on (Itaka et al. 2002) for bone regenerative medicine. Otherwise, a small compound that modulates cGKII activity in vivo would be a good candidate for a new therapeutic drug.

\section{Materials and methods}

\section{Genetic mapping}

Heterozygous (BN $\times$ KMI-mri/mri) F1 rats were backcrossed to KMI-mri/mri homozygous rats to obtain backcross progeny (241 homozygotes among 475 backcross progeny). Animals were genotyped with SSLP markers (Rat Genome Database, http:// rgd.mcw.edu). The segregation patterns of the markers were analyzed with the Map Manager computer program. The ratmouse-human comparative map was constructed based on the data obtained from the following databases: RatMap (http:// ratmap.gen.gu.se), Mouse Genome Informatics (http://www. informatics.jax.org), and University of California at Santa Cruz Genome Browser (http://genome.ucsc.edu).

\section{Positional candidate cloning of the mri locus}

Total RNA from rat intestine was prepared and subjected to RT-PCR using specific primers to amplify overlapping products that cover the coding region of the rat cGKII gene. Genomic DNA was isolated from rat liver, and interexon PCR was carried out with primers as follows: 5'-CTTATCACAGACGCCCT GAATAAGAAC-3' and 5'-CACTTCCAAGCAGTCAATAAT CTTGGT-3'. The amplified pruducts were sequenced using ABI PRISM 310 Genetic Analyzer (Applied Biosystems).

Animals were genotyped with primers as follows: common forward, 5'-TGTATTTTCCCGTCCGACAC-3'; wild-type reverse, 5'-TCCTTCGATGCCACCGTAAT-3'; and KMI reverse, 5'-CAGAGTACGCTAGGTTCCAAGG-3'.

\section{In vitro kinase assay}

Wild-type and KMI brain extracts $(40 \mu \mathrm{g})$ were prepared using T-PER (Pierce). Kinase activity was determined by the phosphorylation of biotinylated substrate peptide $(250 \mu \mathrm{M}$, BiotynylRKISASEFDRPLR-OH, Bachem) in the presence of PKI ( $2 \mu \mathrm{M}$, Sigma) and 8-bromo-cGMP $(100 \mu \mathrm{M})$ for $30 \mathrm{~min}$ at $30^{\circ} \mathrm{C}$ using the AUSA Universal Protein Kinase Assay Kit (TRANSBIO).

\section{Histological analysis}

Tissues were fixed in $4 \%$ paraformaldehyde and decalcified in $10 \%$ EDTA, if necessary, then embedded in paraffin and cut into
6- $\mu \mathrm{m}$ sections. Hematoxylin eosin (HE) staining and von Kossa staining were done according to the standard procedure. For enzyme histochemistry, ALP was visualized using X-phosphate and NBT (Roche). For immunohistochemistry, sections were incubated with primary antibody at $4^{\circ} \mathrm{C}$ overnight. Primary antibodies were purchased from Santa Cruz Biotechnology. Signal was detected with HRP-conjugated secondary antibody. For fluorescent visualization, a secondary antibody conjugated with Alexa 488 (Molecular Probes) was used.

\section{In vivo BrdU labeling}

Animals were injected intraperitoneally with BrdU (Sigma), 25 $\mu \mathrm{g}$ per gram body weight $2 \mathrm{~h}$ prior to sacrifice. Incorporated BrdU was detected using a BrdU immunostaining kit (Roche).

\section{Fracture model}

A fracture was generated on the mid-part of the tibiae of 10week-old animals ( $n=10$ /group). Animals were sacrificed $2 \mathrm{wk}$ after the surgery. Fracture callus was quantitated as described (Shimoaka et al. 2004).

\section{Analysis of growth plate chondrocytes}

Growth plate chondrocytes were isolated from the tibiae of 4-week-old animals as described (Klaus et al. 1991). Cells were cultured in Dubecco's Modified Eagle's Medium (DMEM) supplemented with $10 \%$ fetal bovine serum (FBS). For cellular proliferation assay, $1 \times 10^{5}$ cells were plated on a $6-\mathrm{cm}$ dish and counted after designated periods. To assess differentiation, cells were incubated for a designated period with hBMP-2 (100 ng/ $\mathrm{mL})$ and CNP (100 nM) when needed. They were stained for ALP, and ALP activity was quantitated as described (Shimoaka et al. 2004). RNA was isolated and subjected to semiquantitative RT-PCR analysis. Primer information will be provided upon request.

\section{Plasmids and viral vectors}

cDNA of rat cGKII (nucleotides 48-2333) was ligated into pcDNA4HisA (Invitrogen). A PCR-amplified fragment (nucleotides 48-1403) was used to construct the cGKII- $\Delta$ kinase vector. Full-length human Sox5, Sox6, and Sox9 were ligated into pEGFPC1 (Clontech) to generate GFP-tagged plasmids. To create amino acid change (S181A and S64A), GFP-Sox9 plasmid was subjected to site-directed mutagenesis using the inverse PCR technique. To construct nuclear-localizing GFP-Sox9 vector (Sox9-3xNLS), a three-tandem repeat of SV40-derived nuclear localizing signal was ligated into pEGFPC1. All constructs were verified by sequencing. cGKII and GFP-Sox9 adenovirus vectors were constructed using the Adeno-X Expression System (BD Biosciences), according to the manufacturer's protocol. RNAi sequence was designed for the rat $\operatorname{Sox} 9$ gene (nucleotides 190-219, AB073720.1) as described (Kawasaki and Taira 2003) and ligated into piGENEtRNA vector (iGENE Therapeutics). RNAi sequence combined with promotor was then inserted into pMx vector (Kitamura 1998), and retroviral vector was generated using plat-E cells (Morita et al. 2000).

\section{Cell culture and transient transfection}

HuH-7 and HeLa were cultured in DMEM supplemented with $10 \%$ FBS. ATDC5 was maintained as described (Shukunami et al. 1996). For transient transfection, a total of $1 \mu \mathrm{g}$ plasmid DNA was transfected using FuGENE6 (Roche). In cotransfection, all 
plasmids were added in an equal ratio. 8-bromo-cGMP (100 $\mu M$, BioMol) was added $4 \mathrm{~h}$ after transfection. Total RNA was isolated $72 \mathrm{~h}$ after transfection and subjected to real-time PCR analysis. For fluorescent detection, HeLa cells were transiently transfected and fluorescent images were taken $24 \mathrm{~h}$ after transfection. Cells were incubated with $2.5 \mathrm{ng} / \mathrm{mL}$ leptomycin B (Sigma) for the last $3 \mathrm{~h}$ when required. For the differentiation assay, ATDC5 cells were transiently cotransfected with Sox9 vector $(3 \mu \mathrm{g})$ and a designated amount of cGKII vector. Two days after transfection, a three-dimensional alginate beads culture was performed as described (Seki et al. 2003) in the presence of 8-bromo-cGMP $(100 \mu \mathrm{M})$ and ITS supplement (Sigma). RNA was isolated $7 \mathrm{~d}$ after transfection and subjected to real-time PCR analysis.

\section{Western blotting}

Samples were prepared using M-PER (Pierce) or NE-PER (Pierce) supplemented with $\mathrm{Na}_{3} \mathrm{Vo}_{4}(2 \mathrm{mM}), \mathrm{NaF}(10 \mathrm{mM})$, and aprotinin $(10 \mu \mathrm{g} / \mathrm{mL})$ following the manufacturer's protocol. An equal amount $(20 \mu \mathrm{g})$ of protein was subjected to SDS-PAGE, and transferred onto PVDF membranes. Anti-EGFP antibody (Clontech) and anti-Sox9 $\left(\mathrm{pS}^{181}\right.$ ) phosphospecific antibody (BioSource) were used. The membrane was incubated with HRP-conjugated secondary antibody (Promega). Immunoreactive proteins were visualized by ECL (Amersham).

\section{PTH-induced cAMP accumulation}

Cells were preincubated with 8-bromo-cGMP (100 $\mu \mathrm{M})$ for 30 min, then challenged with increasing concentrations of PTH (Sigma) and incubated at $37^{\circ} \mathrm{C}$ for $30 \mathrm{~min}$ in the presence of IBMX (2 mM). Intercellular cAMP was measured using the cAMP Biotrack EIA system (Amersham) following the manufacturer's protocol.

\section{Statistical analysis}

Means of groups were compared by ANOVA, and significance of differences was determined by post-hoc testing with Bonferroni's method.

\section{Acknowledgments}

We thank Drs. Benoit de Crombrugghe, Sakae Tanaka, Yasuo Terauchi, and Takashi Kadowaki for critical discussions. We also thank Reiko Yamaguchi, Mizue Ikeuchi, and Misako Namae for their excellent technical help. This work was supported by Grants-in-Aid for Scientific Research from the Japanese Ministry of Education, Culture, Sports, Science and Technology (\#14657359 and \#15591566).

\section{References}

Akiyama, H., Chaboissier, M.C., Martin, J.F., Schedl, A., and de Crombrugghe, B. 2002. The transcription factor Sox9 has essential roles in successive steps of the chondrocyte differentiation pathway and is required for expression of Sox 5 and Sox6. Genes \& Dev. 16: 2813-2828.

Chung, U. and Kronenberg, H. 2000. Role of parathyroid hormone-related protein and indian hedgehog in skeletal development. In Skeletal growth factors (ed. C. Canalis), pp. 355364. Lippincott Willams \& Wilkins, Philadelphia.

Chusho, H., Tamura, N., Ogawa, Y., Yasoda, A., Suda, M., Miyazawa, T., Nakamura, K., Nakao, K., Kurihara, T., Kom- atsu, Y., et al. 2001. Dwarfism and early death in mice lacking C-type natriuretic peptide. Proc. Natl. Acad. Sci. 98: 4016-4021.

Daluiski, A., Engstrand, T., Bahamonde, M.E., Gamer, L.W., Agius, E., Stevenson, S.L., Cox, K., Rosen, V., and Lyons, K.M. 2001. Bone morphogenetic protein-3 is a negative regulator of bone density. Nat. Genet. 27: 84-88.

de Crombrugghe, B., Lefebvre, V., and Nakashima, K. 2001. Regulatory mechanisms in the pathways of cartilage and bone formation. Curr. Opin. Cell Biol. 13: 721-727.

Fowkes, R.C. and McArdle, C.A. 2000. C-type natriuretic peptide: An important neuroendocrine regulator? Trends Endocrinol. Metab. 11: 333-338.

Gasca, S., Canizares, J., De Santa Barbara, P., Mejean, C., Poulat, F., Berta, P., and Boizet-Bonhoure, B. 2002. A nuclear export signal within the high mobility group domain regulates the nucleocytoplasmic translocation of SOX9 during sexual determination. Proc. Natl. Acad. Sci. 99: 11199-11204.

Harley, V.R., Clarkson, M.J., and Argentaro, A. 2003. The molecular action and regulation of the testis-determining factors, SRY (sex-determining region on the Y chromosome) and SOX9 [SRY-related high-mobility group (HMG) box 9]. Endocr. Rev. 24: 466-487.

Hofmann, F. 1995. cGMP-dependent protein kinase (vertebrates). In The protein kinase factsbook (eds. G. Hardie and S. Hanks), pp. 73-76. Academic Press, San Diego.

Hofmann, F., Ammendola, A., and Schlossmann, J. 2000. Rising behind NO: cGMP-dependent protein kinases. I. Cell Sci. 113: $1671-1676$.

Huang, W., Zhou, X., Lefebvre, V., and de Crombrugghe, B. 2000. Phosphorylation of SOX9 by cyclic AMP-dependent protein kinase A enhances SOX9's ability to transactivate a Col2al chondrocyte-specific enhancer. Mol. Cell Biol. 20: 4149-4158.

Huang, W., Chung, U.I., Kronenberg, H.M., and de Crombrugghe, B. 2001. The chondrogenic transcription factor Sox 9 is a target of signaling by the parathyroid hormone-related peptide in the growth plate of endochondral bones. Proc. Nat1. Acad. Sci. 98: 160-165.

Itaka, K., Harada, A., Nakamura, K., Kawaguchi, H., and Kataoka, K. 2002. Evaluation by fluorescence resonance energy transfer of the stability of nonviral gene delivery vectors under physiological conditions. Biomacromolecules 3: 841845.

Kawasaki, H. and Taira, K. 2003. Short hairpin type of dsRNAs that are controlled by tRNA(Val) promoter significantly induce RNAi-mediated gene silencing in the cytoplasm of human cells. Nucleic Acids Res. 31: 700-707.

Kitamura, T. 1998. New experimental approaches in retrovirusmediated expression screening. Int. J. Hematol. 67: 351-359.

Klaus, G., Merke, J., Eing, H., Hugel, U., Milde, P., Reichel, H., Ritz, E., and Mehls, O. 1991. 1,25(OH)2D3 receptor regulation and $1,25(\mathrm{OH}) 2 \mathrm{D} 3$ effects in primary cultures of growth cartilage cells of the rat. Calcif. Tissue Int. 49: 340-348.

Kronenberg, H.M. 2003. Developmental regulation of the growth plate. Nature 423: 332-336.

Lefebvre, V., Li, P., and de Crombrugghe, B. 1998. A new long form of Sox5 (L-Sox5), Sox6 and Sox9 are coexpressed in chondrogenesis and cooperatively activate the type II collagen gene. EMBO I. 17: 5718-5733.

Miyazawa, T., Ogawa, Y., Chusho, H., Yasoda, A., Tamura, N., Komatsu, Y., Pfeifer, A., Hofmann, F., and Nakao, K. 2002. Cyclic GMP-dependent protein kinase II plays a critical role in C-type natriuretic peptide-mediated endochondral ossification. Endocrinology 143: 3604-3610.

Morita, S., Kojima, T., and Kitamura, T. 2000. Plat-E: An effi- 
cient and stable system for transient packaging of retroviruses. Gene Ther. 7: 1063-1066.

Pfeifer, A., Aszodi, A., Seidler, U., Ruth, P., Hofmann, F., and Fassler, R. 1996. Intestinal secretory defects and dwarfism in mice lacking cGMP-dependent protein kinase II. Science 274: 2082-2086.

Pfeifer, A., Klatt, P., Massberg, S., Ny, L., Sausbier, M., Hirneiss, C., Wang, G.X., Korth, M., Aszodi, A., Andersson, K.E., et al. 1998. Defective smooth muscle regulation in cGMP kinase I-deficient mice. EMBO J. 17: 3045-3041.

Ruth, P. 1999. Cyclic GMP-dependent protein kinases: Understanding in vivo functions by gene targeting. Pharmacol. Ther. 82: 355-372.

Schipani, E., Lanske, B., Hunzelman, J., Luz, A., Kovacs, C.S., Lee, K., Pirro, A., Kronenberg, H.M., and Juppner, H. 1997. Targeted expression of constitutively active receptors for parathyroid hormone and parathyroid hormone-related peptide delays endochondral bone formation and rescues mice that lack parathyroid hormone-related peptide. Proc. Natl. Acad. Sci. 94: 13689-13694.

Seki, K., Fujimori, T., Savagner, P., Hata, A., Aikawa, T., Ogata, N., Nabeshima, Y., and Kaechoong, L. 2003. Mouse Snail family transcription repressors regulate chondrocyte, extracellular matrix, type II collagen, and aggrecan. J. Biol. Chem. 278: 41862-41870.

Serizawa, N. 1993. Initial characterization of a new miniature animal model in the rat: Studies on anatomy, pituitary hormones and GH mRNA in miniature rat Ishikawa. Nippon Naibunpi Gakkai Zasshi 69: 33-45.

Shimoaka, T., Kamekura, S., Chikuda, H., Hoshi, K., Chung, U.I., Akune, T., Maruyama, Z., Komori, T., Matsumoto, M., Ogawa, W., et al. 2004. Impairment of bone healing by insulin receptor substrate-1 deficiency. J. Biol. Chem. 279: 15314-15322.

Shukunami, C., Shigeno, C., Atsumi, T., Ishizeki, K., Suzuki, F., and Hiraki, Y. 1996. Chondrogenic differentiation of clonal mouse embryonic cell line ATDC5 in vitro: Differentiationdependent gene expression of parathyroid hormone (PTH)/ PTH-related peptide receptor. J. Cell Biol. 133: 457-468.

Sock, E., Pagon, R.A., Keymolen, K., Lissens, W., Wegner, M., and Scherer, G. 2003. Loss of DNA-dependent dimerization of the transcription factor SOX9 as a cause for campomelic dysplasia. Hum. Mol. Genet. 12: 1439-1447.

Sorrentino, V., Pepperkok, R., Davis, R.L., Ansorge, W., and Philipson, L. 1990. Cell proliferation inhibited by MyoD1 independently of myogenic differentiation. Nature 345: 813815.

Stewart, M.C., Kadlcek, R.M., Robbins, P.D., MacLeod, J.N., and Ballock, R.T. 2004. Expression and activity of the CDK inhibitor p57Kip2 in chondrocytes undergoing hypertrophic differentiation. J. Bone Miner. Res. 19: 123-132.

Sudbeck, P. and Scherer, G. 1997. Two independent nuclear localization signals are present in the DNA-binding highmobility group domains of SRY and SOX9. J. Biol. Chem. 272: 27848-27852.

Tao, H. and Umek, R.M. 2000. C/EBP $\alpha$ is required to maintain postmitotic growth arrest in adipocytes. DNA Cell Biol. 19: 9-18.

Umek, R.M., Friedman, A.D., and McKnight, S.L. 1991. CCAAT-enhancer binding protein: A component of a differentiation switch. Science 251: 288-292.

Yan, Y., Frisen, J., Lee, M.H., Massague, J., and Barbacid, M. 1997. Ablation of the CDK inhibitor p57Kip2 results in increased apoptosis and delayed differentiation during mouse development. Genes \& Dev. 11: 973-983.

Yasoda, A., Komatsu, Y., Chusho, H., Miyazawa, T., Ozasa, A.,
Miura, M., Kurihara, T., Rogi, T., Tanaka, S., Suda, M., et al. 2004. Overexpression of CNP in chondrocytes rescues achondroplasia through a MAPK-dependent pathway. Nat. Med. 10: 80-86. 


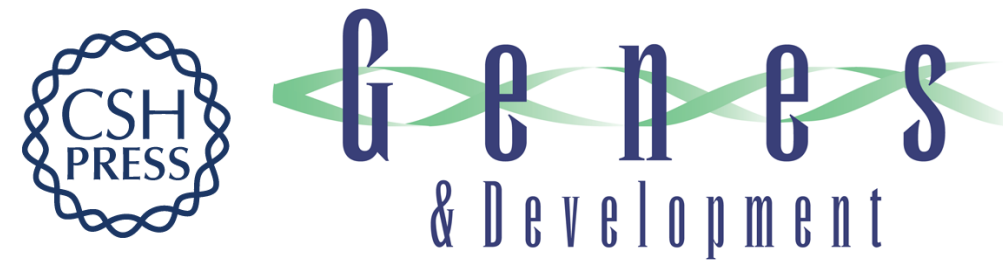

\section{Cyclic GMP-dependent protein kinase II is a molecular switch from proliferation to hypertrophic differentiation of chondrocytes}

Hirotaka Chikuda, Fumitaka Kugimiya, Kazuto Hoshi, et al.

Genes Dev. 2004, 18:

Access the most recent version at doi:10.1101/gad.1224204

References This article cites 34 articles, 16 of which can be accessed free at: http://genesdev.cshlp.org/content/18/19/2418.full.html\#ref-list-1

License

Email Alerting

Receive free email alerts when new articles cite this article - sign up in the box at the top Service right corner of the article or click here.

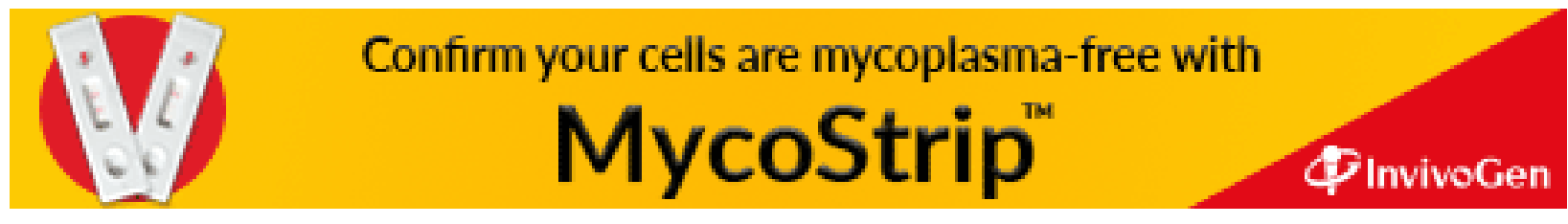

